\title{
La Poesía de Pedro Salinas
}

por

Juan Marichal

Es hoy una muy visible verdad de Perogrullo que el siglo $\mathrm{XX}$ es la segunda edad de oro de la poesía en lengua castellana. Es también igualmente visible que en esta edad de oro se destaca un grupo de poetas españoles - un grupo de amigos muy unidos-el de la llamada "generación Lorca-Guillén" o quizá más propiamente el de la "doble" generación de 1921-1931. Juan Ramón Jiménez, Antonio Machado, Unamuno, el gran Rubén, los iniciadores de este medio siglo de oro lírico son tan grandes poetas como los de esa generación de 1931: pero todos ellos aparecen, irrumpen casi, en la historia literaria de lengua castellana diríase que solitariamente, un tanto adánicamente. Sí, por descontado, Rubén es un poco el padre de los tres españoles, pero, con todo, las yoces de Juan Ramón, de Machado y de Unamunocsurgen un tanto en apartes, en soledades distanciadas: incluso geográficamente, topográficamente, distanciadas. Machado en su provincia castellana o andaluza. Unamuno en su Salamanca anti-cortesana, anti-Madrileña diríamos. Juan Ramón, en su celda, en su soledad en medio de la Corte. Se puede decir un poco de estos poetas, aquello que decía el gran argentino, Sarmiento: "El español se encierra en sí mismo y hace versos". En cambio los poetas del grupo 1931 aparecen casi simultáneamente, y casi juntos - casi como un coro de amigos que cantan juntos. IIay así un indudable simbolismo histórico en la fotografía publicada por Dámaso Alonso, en su libro Poetas españoles contempo. ráneos, del grupo de poetas en su visita colectiva a Sevilla en 1927. Pero en este grupo de amigos tan afines, de vocaciones tan estrechamente paralelas (como las de Guillén y Salinas) cada voz poética es desde el principio, desde su nacimiento mismo, singular, personalísima. Todos se parecen externamente - no hay en ellos, por ejemplo, el manifiesto afán de 
singularizarse en lo exterior de la persona, ese afán tan propio de los del 98- y sin embargo cada uno "canta" su poesía diferentemente. Mas, hay, no obstante esta concordancia en la amistad, y en las aficiones artísticas, un marcado contraste entre el conjunto de estos poetas y uno de ellos, entre los más jóvenes y el de más edad: Pedro Salinas.

Dámaso Alonso apuntó en el libro citado una de las características -o quizá la suma de características- que distinguen a Salinas: "el literato español de más facetas y más aptitudes variadas del momento presente". Tengamos presente por supuesto, que Dámaso Alonso escribe las palabras citadas en 1951. Habla del Salinas de los últimos años, de la gran década final del poeta. Pero es también cierto que esta observación de Dámaso Alonso tiene consecuencias retrospectivas: de todos aquellos poetas de la llamada generación de 1931 Salinas es el único cuya obra abarca casi todos los géneros literarios, incluyendo en éstos la crítica y la historia de la literatura. Mas hay también otro contraste quizá no observado hasta ahora: Salinas, el hermano mayor, como uno de ellos ha dicho, es sin duda alguna (en la década 1923-1933) el poeta de voz menos segura de sî misma, es el poeta menos él mismo de todo el grupo. O dicho en otros términos, Salinas, el de más edad del grupo. no es todavía el Salinas - poeta que conocemos, mientras Guillén. Lorca, Alberti, son ya claramente, Guillén, Lorca, Alberti. En el caso del poeta más amigo de Salinas, y más próximo a él en edad, Jorge Guillén, es muy marcado el contraste: en 1923, cuatro años antes de la primera edición o versión de Cántico, aparecen poemlas de Guillén en la revista España que son ya definitivamente guillenianos. Y me atrevo a proponer ahora que el Salinas de Presagios - publicado en 1923 - es sólo un pre-Salinas, un Salinas tendiendo hacia sí mismo, un Salinas antes de ser Salinas.

Consideremos de nuevo el contraste apuntado por Dámaso Alonso. Diríase que ese contraste se podría también exponer en los siguientes términos resumiendo lo que he señalado yo mismo: los poetas del grupo 1921-1931 son, con la excepción de Salinas, poetas que Ilamaríamos unitarios, de una sola vía o si se prefiere de un solo fundamento, de un solo cimiento. El ejemplo o la norma del grupo está claro en la construcción piramidal, o quizá más exactamente catedralicia del Cántico guilleniano: el poeta ha erigido su voz sin dudas y sin desvíos. Mas, en casi todos ellos hay quizá en virtud de su misma seguridad inicial, de su primera confianza en la propia voz, una lírica que admite pocas ampliaciones. 
En la obra de Salinas, en su totalidad, se observa, en cambio, una ampliación temática, un como despliegue vital que confiere finalmente a su poesía un carácter a la vez muy singular y muy universal dentro de la lírica en castellano del siglo XX. o sea que la hipótesis histórico-literaria que quiero someter a la consideración del lector es la siguiente: Salinas, la voz más titubeante de su grupo de amigos españoles, antes de 1933, viene a ser al acabar su vida y su obra una de las voces poéticas de mayores resonancias humanas en nuestro tiempo.

El proceso o la trayectoria de la expresión, de la condición poética en Salinas es incluso para mí muy representativo de un proceso humano general, de un proceso que define quizás la vida de muchos hombres. Este proceso lo ha resumido asi un gran pensador y un gran hombre de nuestro tiempo cuya obra alcanzó a conocer Salinas en sus últimos, muy últimos años: Tcilhard de Chardin. El secreto de la posible plenitud humana, del posible equilibrio interno del hombre lo ve Teilhard de Chardin en esta forma: $1^{\circ}$ se centrer sur soiememe, $2^{\circ}$ se décentrer slï l'autre, $3^{\circ}$ se surcentrer sur un plus grand que soi. Centrarse en sí mismo, descentrarse en el otro, sobrecentrarse en el Uno mayor que uno mismo. Voy ahora a intentar exponer cómo la vida de Salinas en cuanto poeta, cómo la obra poética de Salinas, res. ponde muy fielmente a este esquema humano, a esta trayectoria humanísima. La vida de Salinas - ateniéndonos exclusivamente a los datos de su actividad literaria- se divide en tres fases, la primera, que corresponde a las dos décadas 19131933, es la fase de lo que podríamos denominar fase de encentración, la segundale 1933 a 1936, es lâl fase que podríamos denominar de descentración en el tú de la amada, y la tercera de 1936 hasta 1951, es la fase final de sobre-centración en el Uno del Contemplado, en el Uno mayor que el hombre. El proceso poético de Salinas podría resumirse así: 1: el tanteo hacia la propia voz y hacia el propio yo, $2^{\circ}$ el encuentro del yo al hallar al tú del amor humano, y 3 : la ampliación de la voz al tú debida hasta transformarse en la voz al contemplado entregada.

Consideremos ahora la primera fase de la obra poética de Salinas, la de las dos décadas 1913 - 1933. Salinas, que había nacido en $1891-\mathrm{y}$ no en 1892 , como siguen diciendo la mayor parte de los textos de historia literaria y como decía el mismo Salinas - publicó en 1911 sus primeros poemas, en el número 32 de la revista Prometeo, fundada en 1908 por Ramón Gómez de la Serna. Salinas tiene, pues, veinte años cuando publica unos poemas que titula "Estrofas" y que firma 
"Pedro Manuel Salinas". En la revista de Gómez de la Serna coexisten dos grupos, uno que a la larga se destacará como innovador (el mismo Ramón, Salinas) y otro que será completamente olvidado o casi (Emilio Carrére, Antonio de Hoyos). Los dos grupos coinciden, relativamente, en un solo aspecto, el decadentismo del modernismo finalizante. Las "Estrofas" de Salinas están completamente dentro de ese ámbito literario. Citemos algunos versos de la primera: "Yo ya había leído a Lamartine. Alguna/ vez también en secreto, hice más de una rima./ $\mathrm{Y}$ esa noche de abril, clara noche de luna,/ era altar el piano y era diosa mi prima./ Aquella prima rubia.../ Se llamaba Consuelo. Era rubia y coqueta/ y fue un arco triunfal, su perversa inocencia,/ pQr el que entró mi alma cansada de pocta/ en el jardín de esta lírica adolescencia".

En estos versos hay indudablemente una voluntad de ser "decadente": no son, por supuesto, la emanación espontánea de un adolescente ingenuo. Son muy al contrario, la expresión de un adolescente bastante sophisticated de ese momento. Salinas es entonces amigo de su compañero de generación Ricardo Baeza, que tenía una tertulia en la pensión donde vivía y en esa tertulia se conocieron muchos jóvenes españoles de entonces: por ejemplo, no hace mucho el político Alvarez del Vayo ha recordado en su autobiografía que allí se conocieron él y Salinas. No podemos ahora detenernos a hablar de Baeza y de su importancia en la sociologia de la literatura contemporánea de lengua castellana, baste señalar que el joven Baeza quería hasta cierto punto ser entre un Wilde y un Remy de Gourmont en la vida de la España diterarja.) Pero Salinas se apartó de esa línea "đecadentista"-línea que en ciertas formas exteriores tipográficas, por ejemplo, es todavía visible en la revista La Pluma, publicada por los amigos de Baeza, Manuel Ażña y Cipriano Rivas Cheriff, años más tarde. Salinas, puede decirse, abandona casi en seguida esa voz falsa, que no le corresponde-que no puede ser la suya, y empieza a luchar- para decirlo con versos suyos del libro Presagios: "por dar con el secreto del movimiento justo para mi verbo". En 1913 concluye los estudios de la licenciatura en letras y en 1914 marcha a la Sorbona de lector de literatura hispánica. En 1915 se casa con Margarita Bormatí, argelina de familia levantina a la que había conocido en un pueblecito de la costa Alicantina, Santa Pola. Escribe entonces los primeros poemas de Presagios, probable. mente muy poco a poco, como dice en el primer poema de este libro: "Forjé un eslabón un día/otro día forjé otro/y otro".

En la revista España, fundada por Ortega en 1915 - que tan 
importante había de ser en la vida cspañola del septenio siguiente- publica Salinas en 1916 un poema "La palma y la trente", no recogido en Presagios. No podemos decir que este poema es ya "salinesco" ni quizá completamente cl segundo publicado por Salinas en España, en 1918, y este sí recogido en Presagios, el tercer poema de este libro, cuyo verso inicial es "Mis ojos ven el árbol". Está ya ahí, sin embargo, el verso de Salinas: no todavía la voz entera de Salinas. Otro poema, "Voz de jugar" -que tampoco está en Presagios- aparece en 1920 en el primer número de la revista La Pluma, ya mencionada. Versos muy deliberadamente prosaicos: "Yo iba poniendo los naipes/ uno al lado de otro, todos/ trabados por voluntad/ y no por su peso propio". Pero ya apunta más claramente un tono pre-Salinas en los siguientes: "Y mientras el alma oye/ voz de jugar y dudar,/ las dos manos/ sobre los naipes se van/ a salvarlo todio, $y$ vieiveni a cmpezar".

Recordemos -haciendo un breve paréntesis biográficoque desde 1918 Salinas es catedrático numerario de literatura española en la Universidad de Sevilla. Desde su regreso a España ha vuelto a unirse al grupo de colaboradores de don Ramón Menéndez Pidal en el Centro de Estudios Históricos. Pero en Salinas no hay ninguna utilización en su creación poética de la poesía tradicional restaurada o salvada por don Ramón y su escuela: quiero decir que en este aspecto hay un contraste muy grande entre Salinas y los andaluces Lorca y Alberti. Estos se apoyan en la poesía tradicional, diríamos que a ella le deben su voz primera y quizá su voz mejor, mientras que en Salinas no hay literalmente traza de la poesía tradicional. En el mismo Guillen hay una presencia de toda la poesía española, de todo el pasado métrico hispánico: y hasta abundan en Guillén, como mostró el mismo Salinas, los romances. En Salinas la no utilización de la poesía tradicional, el no sustentarse en un rico legado lírico está muy relacionado, a mi ver, con su aspiración a encontrar la propia tonalidad, el movimiento justo para su verbo. Observemos que Salinas no figura propiamente en el romancero contemporáneo y sin embargo como ha señalado Francisco García Lorca (en uno de sus cursos universitarios) hay en Salinas un muy propio romancismo. Esto es, Salinas citando la definición del romance dada por Juan de Valdés ("hilo de decir que va continuado y llano") decía que "el romance invita a extenderse sin prisa, a deiarse llevar por el correr de los versos". Esto es lo que manifiestamente está buscando Salinas: un fluir continuado y llano de la poesía, una poesia que sea toda ella un solo largo poema. 
¿Por qué? Aquí nos acercamos al Salinas que va a aparecer hacia 1933. Porque la poesía de Salinas quiere ser una confidencia, quiere ser una continua confidencia. En el poema 19 de Presagios se decía "todo/ era como un corazón/ tendido a la confidencia". Si cotejamos Presagios con los dos libros siguientes de Salinas, Seguro Azar y Fábula y Signo, observamos que el poeta está empleando más y más la segunda persona de singular, está más y más tendiendo hacia ese $T u ́$ que es la primera palabra del libro La Voz a ti Debida, de 1933. Claro, la diferencia es fundamental entre el tí anterior a $L a V o z$ y el de este libro. De Presagios a $L a V o z$, es decir en la década 1923-1933, el tú es un pronombre que podríamos llamar indiferenciado, mientras que en los libros de 1933 y 1936, La Voz y Razón de Amor, el tú es exclusivamente el de la mujer amada.

Pero antes de considerar la obra que primero expresa al poeta Salinas, es menester detenerse en lo que hemos indicado, en la necesidad confidencial del poeta, en el ascenso hacia la plena confidencia que es la obra de Salinas. Aquí es mencster también hacer un breve paréntesis metodológico, considerar muy someramente la relación entre obra y vida, entre poesía y biográfía. Todos recordamos sin duda la introducción de Salinas a su estudio sobre Rubén Darío y cómo insiste en los peligros de la tendencia biografista, en la tendencia muy visible en nuestro tiempo (particularmente en autores franceses) que confunde al hombre con el poeta al creador con el "vecino de al lado", como dice Salinas. Salinas concluía esa introducción diciendo: "Todo esto son precauciones que nos calzamos antes de atrevernos a hablar de la vida de Rubén Dario". Yo no voy ahora, desde luego, a hacer la biografía de Salinas, pero, sí quisiera permitirme un muy breve paréntesis y apuntar algunas observaciones biográficas. Los amigos más antiguos nodrán decirme si me equivoco en este esquemático esbozo de semblanza. Yo diría que Pedro Salinas era un hombre a la vez abierto y tímido, extraordinariamente expansivo y sin embargo cerradamente pudoroso. Es verdad que en todas las tierras de lengua castellana se dan paralelamente estas dos tendencias, aparentemente opuestas, en muchos, muchísimos hombres. Pero en Salinas quizá las dos caracteristicas tomaban rasgos extremados: norque pocos españoles habrán habido más expansivos, más abiertos de su persona y, sin embargo, pocos hombres españoles habrán también habido más intimamente pudorosos. Yo casi casi me atrevería a decir que la expansividad y el pudor eran en Salinas como el anverso y el reverso de su persona. $O$ expre- 
sado en otros términos, Salinas era expansivo con sus amigos, pero dudo mucho, muchísimo, que Salinas haya tenido nunca "amigotes", en el sentido castizo de la palabra, que se haya intimamente confiado en otros hombres. Claro está, se puede decir que esto sucede con frecuencia; y que su consecuencia lógica sucede también con frecuencia. Me refiero a la confidencia del hombre con la mujer, hacia la mujer.

Aquí conviene hacer una observación importante. Salinas - como es ya muy sabido- era un fecundísimo escritor epistolar. Sus cartas se pueden dividir en dos clases: las cartas expansivas a los amigos, las cartas en que se comenta hurnorísticamente y a veces dolorosamente todo lo que acaece en este planeta y. las cartas totalmente íntimas, las cartas dirigidas por ejemplo a Margarita Bormatí. Hace algunos años, gracias a una antigua amiga de Salinas, Pepita Baile, en cuya casa de Santa Pola conoció Salinas a la que había de ser su esposa, vino a mi poder la casi totalidad del epistolario de noviazgo de Salinas. El mismo Salinas insistía en la importancia en la formación de ciertos escritores de su epistolario de mocedad (el de Unamuno, por ejemplo, con su novia). También este epistolario de Salinas es muy importante. $Y$ aunque estimo que por ahora - ni tampoco quizá más tarde- es necesario publicar esas cartas, que son, después de todo, textos esencialmente privados, puedo asegurar que hay una indudable relación entre el estilo expresivo de Salinas en ellas y el de su poesía. Pero como no se ha dicho suficientemente en nuestro tiempo, un poeta está en su obra, Sestá en su poesía. Algunos críticos y pseudobiógrafos han querido apoyarse en Goethe para afirmar - como Goethe lo hacía según ellos que la sustancia poética es la sustancia de la propia vida. Pero Goethe al referirse a la propia vida no alude evidentemente a la biografía visible; la propia vida equivale en este caso al mun. do interior del poeta, a los dominios interiores del poeta, a la vida del poeta en cuanto poeta.

Volvamos a la poesía de Salinas, a la poesía de la década 1923-1933. Yo diría que es visible en esos textos el encaminamiento hacia la confidencia, el esfuerzo a la vez expansivo de la confidencia, y el freno represivo del pudor. La confidencia parte siempre de un sentimiento de separación, de un deseo de unir por la palabra, con la palabra, de romper la ausencia. En Proust (cuva obra Salinas traduce) la falta de acceso a la intimidad de la otra persona, el sentimiento doloroso de la separación a priori, es central en su obra, que es quizá en muchos sentidos una vastísima confidencia: "Combien je souffrais 
de cette position oú nous a réduit l'oubli de la nature qui, en instituant- la división des corps, n'a pas songé á rendre possi ble l'interpénétration des ames". Salinas, en Presagios dirá: ...en el pecho/ siento un vacío que sólo/ me lo llenará ese alma/ que no me das". El poeta quiere tender su confidencia hacia $e^{!}$ alma de la amada: pero, al mismo tiempo, debe hacerlo con sumo cuidado. El poeta sabe justamente que la amada quiere guardar su secreto -o más precisamente aún, quiere ser secreto- el poeta sabe que la amada y el pudor son casi consustanciales. Simone de Beauvoir mantiene acertadamente a mi ver que el pudor es, cito textualmente, "un refus spontané de se laisser saisir comme chair", un negarse espontáneamente a dejarse apresar sólo como carnalidad. Simone de Beauvoir añade que en esto hay algo de hipocrecía, sobre todo femenina. Pero, Lucien Romier le contesta avant la lettre, en su libro de 1930, La promotion de la femme, diciendo que el verdadero pudor, en la mujer, "n'est rien que le sentiment de sa dignité". Esto es lo que siente Salinas, y diriase que doblemente: en el pudor está la dignidad de la amada y la confidencia del amador, de todo el que quiere "decir" su amor. Exponer visiblemente el amor es casi transformarlo en grito hambriento, es como bajarlo al nivel de la simple espontaneidad animal. No decirlo, por otra parte, equivale a negarlo. El poeta debe encontrar la voz que revela su secreto -y que no quiere tampoco romper el secreto de la amada - y que sin embargo no lo traiciona, no lo desvirtúa. Diríase que Salinas no está, aún en los libros anteriores a 1933, en el nivel justo de la confidencia, en la voz precisa de la confidencia. De ahí que yo considere que 1933 . la publicación de Las voz a tí debida, es el año realmente inicial del Salinas poeta, del gran poeta Salinas; y que proponga que la voz al tú debida, es también en gran medida, la voz a la confidencia debida.

Pero detengamos ahora nuestra atención en ese año, 1933, y en la publicación de La voz a tí debida. Recordemos, en primer lugar, que todos los lectores escritores - todos los que entonces escriben sobre poesía- señalan inmediatamente que se trata del gran libro de Salinas, y que además se trata de un verdadero acontecimiento en la lírica amorosa española. Desde Azorín, que le dedica uno de sus ensayos en el diario Ahora, "La interferencia apasionada", hasta la revista Cruz $y$ Raya que le dedica una especie de homenaje (tres largos ensayos de José María Quiroga Plá, Luis Rosales y Luis Vivanco), pasando por la Revista de Occidente, con un artículo muy acertado de José Antonio Maravall. Lo que éste dice viene a 
resumir la impresión y el juicio de todos los lectores aludidos: "este libro de Salinas tiene una novedad, algo que no estaba en los anteriores, $y$ es ofrecer impensadamente en el primer poema del libro el ser al descubierto de su poesia". Quizá no tan impensadamente, quizá más deliberadamente, más valientemente de lo que parecia.

Pero, para verlo, para fijar con precisión la originalidad de La voz a tí debida conviene situarla en la biografía poética de Salinas, y hasta en la historia general española. Téngase presente que Salinas tenía entonces cuarenta y dos años, que estaba entonces, con su generación no sólo literaria sino también política, para decirlo orteguianamente en el poder. Eran los tiempos primaverales de la Segunda República y Salinas ocupaba cargos muy importantes en la administración universitaria de aquel régimen. Y sin embargo, Salinas - varón sumamente respetado, sesudo varón, diriamos- publica entonces, año de 1933, un desnudo libro de amor, un poema abiertamente, y hasta podría decirse que violentamente, impúdicamente amoroso. Claro, al decir impúdicamente ahora tendríamos que hacer una importante distinción. Max Scheler decia que hay dos pudores, el pudor corporal o físico y el pudor psiquico. No vamos a entrar ahora en esta distinción, en su aspecto general, pero sí diría que esto se aplica al Salinas de 1933. En él continúa habiendo un extraordinario pudor corporal -mayor que en muchos otros escritores-y sin embargo no hay el pudor psíquico en cuanto se refiere a la expresión poética, al Salinas poeta. Esto se ve claramente en una conferencia suya de 1933 cuando todavía está en prensa su libro, en Barcelona, en la sociedad llamada Amigos de la Poesía. En muy pocas ocasiones, en poquísimas, accedió Salinas a hablar de su poesia. Una de ellas, en 1933, otra, muy poco antes de su muerte, en Wellesley, en 1951. Es posible que Salinas leyera un texto, no lo sé, pero probablemente siguió, como hacia con frecuencia, un guión. Conocemos, sin embargo, el 1esumen publicado por un diario de Barcelona. Salinas insiste en la extrañeza de la poesía para el propio poeta: "Poesía es un formidable movimiento pendular, de fuera adentro. $Y$ hay en ello ensimismamiento, pero también enajenación. Este elemento ajeno es el otro que hay en el poeta: por ello al terminar un poema se experimenta una sensación de despedida".

Salinas concluía su lectura diciendo que durante ella se había enfrentado con su yo extraño. En esa misma visita a Barcelona, Salinas dio otra conferencia en que no habló directamente de su propia poesía, pero al hablar de la poesía se refi- 
rió evidentemente a su propio quehacer poético. Terminaba así: "El poeta es siempre un pasajero y cuando menos se espera es arrebatado a un mundo distinto". Añadamos también que Salinas citaba con frecuencia en sus cursos -están las citas en sus notas de clase- las siguientes palabras de Paul Valéry: "Quand l'inspiration s'annonce je différe déjá de moi - méme... Je suis autre que je ne suis..." Añadía Valéry, y esto aparece también en las notas de Salinas: "C'est ce que je porte d'inconnu en moi qui me fait moi".

Con todo esto quiero apuntar a un aspecto esencial de $L a$ Voz a tí debida. Salinas, hombre importante, en la vida pública española, se atreve a publicar un apasionadísimo libro amoroso porque él supone, presupone, que sus lectores no se prestarán al juego caprichoso de confundir hombre y creador, el Salinas poeta y el Salinas eficaz administrador universitario. Porque Salinas espera que sus lectores vean que toda gran confidencia artística es sólo posible si no se quiere romper la indispensable, la imprescindible dualidad de vida y creación, de biografía y poesía. Nada más peligroso y nada más falso, habría dicho Salinas que la actitud de esos profesores de literatura que no cejan hasta que han considerado todas las posibilidades de explicación biográfica. Menos una, la que en general suele ser la decisiva, la más importante

Una escritora que quizá sea uno de los más importantes pensadores literarios de nuestro tiempo, Claude-Edmonde Magny, en su libro Les sandales d'Empédocle, afirma que en la verdadera creaciónliterariacẹhescriton necesita sentirse libre, $\mathrm{v}$ por lo tanto. ha de situarse forzosamente en lo aue nosotros llamariamos ahora. "el retiro del nseudónimo". Así mantendríamos que Salinas al públicar $L a$ voz a tí debida hace uso de su propio nombre y apellido como si fueran un pseudónimo. Insisto en esto porque me parece inseparable de la naturaleza misma del poema de Salinas: porque el poeta Salinas, en cuanto poeta, entrega ahí su voz total a la poesía al "otro yo" creador.

Quizá Jorge Guillén apuntaba esto en una conferencia (nunca publicada) sobre $L a$ voz a ti debida a raíz de su publicación. Guillén decía en 1934 que el poema de Salinas representaba en la tradición lírica española lo mismo que el Canto a Teresa había representado en el romanticismo. Quizá Guillén señalaba sobre todo la gran semejanza del impacto emocional en los hombres de las épocas respectivas (las Españas de 1844 y de 1933) del Canto a Teresa y de La voz a tí debida. 
Pero hay una gran diferencia, una radical disparidad entre el romántico y Salinas. Porque en Espronceda hay confesión, mientras que en Salinas hay confidencia. O dicho en otros términos, en Espronceda vemos que el poeta ha decidido confesarse, que nos está preparando para la confesión. Charles Le Chevalier ha dicho en su magnifico estudio La conficlence et la personne humaine que la confidencia excluye la intención de hacerla, y exige una especie de irrupción. Porque si hay intención visible de llegar a la confidencia se transforma la expansión del escritor en algo negador de esta confidencia, en el gesto teatral de la confidencia. Por cso en Salinas, antes de 1933, apenas hay indicios de lo que va a decir claramente en 1933, de la irrupción confidencial de 1933. El poeta está a la espera de su voz, trabaja hacia ella, pero no puede decirse que haya una intención artística de marcha hacia esa voz. Le Chevalier observa que casi se puede mantener que el arte excluye la confidencia puesto que el arte se funda en el trabajo intencional del artista. $Y$, sin duda, es impensable la confidencia en ciertos artistas supremos de la palabra: Quevedo o Valle-Inclán, Gracián o Borges, son tan señores de su palabra, tan artísticamente dominadores, que en ellos no puede darse la confidencia. Al contrario de lo que ocurre en la suprema confidencia en lengua castellana, en Santa Teresa: en ésta no hay estrictamente intención artística y por eso su vía expresiva es siempre la de la confidencia. La confidencia hace violencia al escritor, tiene algo de fuerza imperiosa: de ahí que se sienta en $L a$ voz a tí debida sueráfaga rebelde, ese "desgarramiento brutal" que la confidencia impone.

No debe deducirse de lo indicado que Salinas adquiere de pronto en 1933 carácter de poeta un tanto "desmelenado". Aquí conviene de nuevo insistir en la distinción entre poesía y biografía, conviene ser totalmente crociano (a pesar de lo que digan críticos más o menos sutiles): "La sinceridad del poeta -decía el gran italiano- es la de su momento poético". Cuando hablamos de la confidencia de Salinas nos referimos, por lo tanto, exclusivamente a la persona del poeta- a la perso. nalidad poética del poeta- al otro que Salinas llevaba dentro, a la verdad poética de la segunda fase "teilhardiana" de su obra.

Como he ocunado con cierto detalle de la tercera y final fase de la biografía poética de Salinas -en uno de los volúmenes del Homenaje a Dámaso Alonso- no quisiera ahora repetir lo que ya está impreso allí. Debo señalar sin embargo que esa tercera fase corresponde sobre todo a los años de la 
residencia del poeta en tierras americanas, de 1936 hasta su muerte en 1951. El libro más representativo de esa fase es sin duda el largo poema escrito en Puerto Rico, El Contemplada Podríamos decir que Salinas entonces busca el "sobrecentrarse en el Uno más que uno" de Teilhard de Chardin. El afán del poeta es encontrar una voz que represente algo más amplio que el amor individual: no puede decirse que en Salinas hubiera entonces una conversión de tipo religioso. Se trata más bien de un proceso de arraigo en la vida. de verse a sí mismo dentro de la continuidad humana.

Este nroceso lo veo además representado muv gráficamente en los versos que marcan el paso del libro ć.e 1933. La vo? a ti debida, al Contemplado de 1946. El título del libro de 1933 procede como es sabido de un verso de Garcilaso, de la Egloga III:, y en El Contempladn, el título de la Variación $7^{a}$ es el verso de San Juan de la Cruz, "Las ínsulas extrañas". Pues bien, yo diría que la trayectoria poética y humana de $\mathrm{Sa}$. linas equivale al paso de Garcilaso a San Juan, equivale al paso de la poesía debida al tú de la mujer amada, a la poe. sía vertida hacia un Más allá, hacia un humanizador Más allá del hombre. Todos recordamos que Dámaso Alonso mantiene que un conocido texto del siglo XVI, un Garcilaso "a lo divino", es el puente poético y expresivo que lleva de Garcilaso a San Juan: en Salinas yo diria que ese puente no es literario sino geográfico, y muy real, ese puente es la ínsula, diríamos, de Puerto Rico. Porque el poeta dio en Puerto Rico el paso hacia el Uno del contemplado, el poeta sintió allí lo que San Juan llama "este toque de Dios", el toque de una fe humana, de una fe en la más arraigada humanidad, que transformó, sin cambiarla, su voz poética. El gran poeta romántico, Shelley (muy admirado por Salinas) dice en $A$ defence of poetry: "A man, to be greatly good, must imagine intensely and comprehensively; he must put himself in the place of another and of many others..." La obra de Salinas en la última fase de su vida, en la década final, es precisamente ese ponerse en el lugar de otros hombres, de muchos otros hombres. 